\title{
THE COMPENSATION MECHANISM OF CERVICAL MUSCLE DYSFUNCTION ON SPINAL STABILITY - AN IN VITRO STUDY USING PORCINE MODEL
}

\author{
Chih-Hsiu Cheng, Pei-Jing Chen, Ya-Wen Kuo, and Jaw-Lin Wang*
}

\begin{abstract}
Muscle injury/mpairment tesults in decreased muscle forces. Decreased nuscle forces can be compensated by synergic muscle forces. However, the effects of muscle dysfunction and compensation on spinal stability are not clear yet. Eight porcine cervical spine specimens ( $\left.\mathrm{C}_{2}-\mathrm{T} 1\right)$ were tested by the spine flexibility testing apparatus. The apparatus was equipped with muscle force replication of three paired cervical nuscles. The simulations of muscle recruitment included; no muscle recruitment, normal muscle recruitment, muscle dysfunction without compensation, and muscle dysfunction with two compensation strategies: the minimized muscle forces and the minimized axial forces. The spinal stability was examined by the neutral zone (NZ) and range of notion (ROM), which was the sagittal motion of specimen applied with external moment at 0.5 and $2 \mathrm{Nm}$ respectively. Initial positions of specimens were also recorded. NZ and ROM were largest in the no muscle test, and smallest in the muscle dysfunction without compensation test. NZ and ROM of muscle dysfunction with minimal axial force compensation were larger than those with minimal muscle force compensation. This study concluded that: (1) the muscle dysfunction without compensation constrains spinal motion; (2) impaired muscle with compensations cannot stabilize cervical spine efficiently as normal muscles does; and (3) compensation strategy of minimal muscle forces provides better spinal stability than that of minimal axial forces.
\end{abstract}

Key Words: cervical spine, stability, muscle force, muscle dysfunction.

\section{INTRODUCTION}

An unstable spine is clinically defined as the state of excessive spinal motion beyond the normal physiological limits (Nachenson, 1985). Muscles are important in maintaining the spinal stability by increasing the bending stiffness (Essendrop et al., 2002; Lee et al., 2006). Muscular disorders from repetitive work or strain injuries in the neck region distort muscle responses (Andersen ef al., 2007). Impaired muscles usually show decreased muscle force, and can be compensated for by intact synergic muscles (Edgenton et al., 1996). The effect of compensation for impaired muscles on spinal stability is, however,

*Corresponding anthor. (Tel: 886-2-33665269; Fax: 886-223687573; Email: jlwang (entu.edt.tw)

The authors are with the Institute of Biomedical Engineering, National Tawan University, Tawan, R.O.C. less understood.

The issues of spinal stability controlled by the active muscular system are complicated since the numbers of muscles surrounding the spinal segments are larger than the degrees of freedom of the musculoskeletal system. Previous studies examined the relationship between muscle forces and spinal stability by the biomecharical models (Crisco et al., 1991; Snijders et al,, 1991) or the EMG-driven models (Hughes et al, 1994, Langenderfer et al,, 2005), Since the musculoskeletal system is static/lynamic indeterminate, the numerical optimization method is frequently used in those models to solve indeteminate problems of the muscaloskeletal system (Choi et al. 1999; Moroney et al., 1988). The nondinear cost functions such as sum of square muscle forces or sum of square spinal loads are used to minimize the consumed energy or to minimize the compressive stress on the intervertebral disc respectively. The 
optimizations subject to those cost functions are con monly presumed to comply with the control stategy of the central nerve system (CNS) (Arjmand et al. 2006 Brown et al, 2005, Bltchanan et al, 1996 ).

Previous in vitro studies showed the feasibility of using mechanical truscle simulations to study the spinal stability (Danjabi et al, 1989; Wilke et al., 1995). Kettler et al (2002) focused on the cervical muscle fotces and showed that the simulation of six cervical muscles strongly stabilizes the intact of injured upper cervical spine specimens. Nevertheless, the muscle dysfunction and compensation conditions have been less addressed in the in vitro studies.

This in vitto study used porcine spine models to investigate the mechanism of muscle compensation strategies of moured nuscle on tho cervical spine stability The optmization nethod of minimal muscle force and minmal axial force was used to derive the muscle torces. The results of this study may help to clarty: 1 ) the effect of mpared muscles on spinal stability,2) the effect of impared muscles with conpensation strategy on spinal stability, and 3) which compensation strategy provides better spinal stability.

\section{MATERIALS \& METHODS}

\section{Testing Apparatus}

The spine flexibility testing apparatus, which comprised a frame construct, a force replication system and a motion acquisition system, was used (Fig 1). The force replication systeru can generate external pure moments and simulate muscle forees on the specimen. It included a jig with two parallel plates. Two cables were attached to each plate to generate pure moment, and six cables were atached to the jig to simulate the muscle forces. The jig was to clamp the cranial part of the specimen. The weight of the jig was counter balanced throughout the test by a weight hung over the traveling pulley. The two cables of each phte were pulled through sideways pulleys with equal weight pulling in the opposite direction. A total of fourcables on the paralel plates produced two equal force couples to create pure moment. The fine tune tackles were used to adjust the height of sideways pulleys to keep the tangential forces from the four cables horizontally. The adjustunent ensured the applied moments were constant during the defor mation of the spine specinen (Panjabi, 2007).

The muscle pairs of the curent study included symmetrical neck flexors (stemocleidomastoid; SCM) andextensors (splenius capitis, SPL, semispinalis capitis, SSC), which are the man cervical muscles in mantaining the neck dynamie stability (Vasavada et al, 1998), Each muscle force was generated by a given weight so as to keep it a constant force during

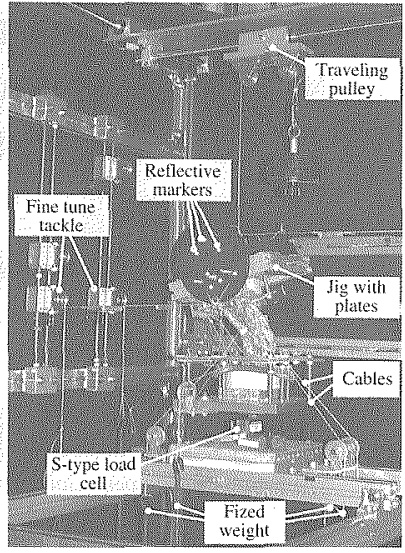

Fig. I Spinal musele replication system

the whole test session. The orientation of each muscle, which was defined by the origin and insertion of the major muscle bands, was determined using the results of a previous study (Vasavada et $\mathrm{al}$, 1998) (Fig. 2). The resultant forces on the specimens were measured by an S-type load cell (STC-50kgSE, Vishay, USA) placed below the specimen.

A two-camera stereophotogrammetric analysis system was used to determine the three-dimensional motion of the specimen. Three reflective makers were placed on the jig for the measurement of motion. The direct linear transformation method was used to transform the $2 \mathrm{D}$ images into rotational angles of three axes. The angular resolution of the motion acquisition system is higher than $0.2^{\circ}$ over the range of $.90^{\circ} \sim 90^{\circ}$ verified by absolute angles from an index plate. The motion acquisition system was calibrated before each testing.

\section{Specimen Preparation}

Eight cervical spines (C2-T), length: $14.9 \pm 0.8$ cm) from 6 month-old swine were used. The muscular tissues of specinens were removed and the specimens were frozen at $-20^{\circ} \mathrm{C}$ for storage. The specimens were moved to a refrigentor $\left(4^{\circ} \mathrm{C}\right)$ one night before lesting and were thawed at room temperature for five hours before testing. The cranial and caudal vertebrae were potted with polymethylmethacrylate. The cranial part of the specimen was clamped by the jig, and the caudal part was fixed on the mounting table of the frame. During the experiment, the specimens were moisturized with saline-soaked gauze. 
Table 1 Magnitude of muscle forces (unit: $N$ ) in different muscle recruitment tests

\begin{tabular}{|c|c|c|c|c|c|c|}
\hline & $\mathrm{SCM}_{\mathrm{R}}$ & $\mathrm{SCM}_{\mathrm{L}}$ & $S P L_{R}$ & $\mathrm{SPL}_{\mathrm{L}}$ & $\mathrm{SSC}_{\mathrm{R}}$ & $\mathrm{SSC}_{\mathrm{Z}}$ \\
\hline Normal muscle recruitment & 18 & 18 & 13 & 13 & 17 & 17 \\
\hline SCM dysfunction without compensation & 4 & 18 & 13 & 13 & 17 & 17 \\
\hline SCM dysfunction with minimal muscle force compensation & 4 & 4 & 1 & 1 & 18 & 18 \\
\hline SCM dysfunction with minimal axial force compensation & 4 & 3 & 0 & 1 & 35 & 1 \\
\hline
\end{tabular}

Subscripts " $R$ " and " $L$ " indicate the right and left side muscle respectively.

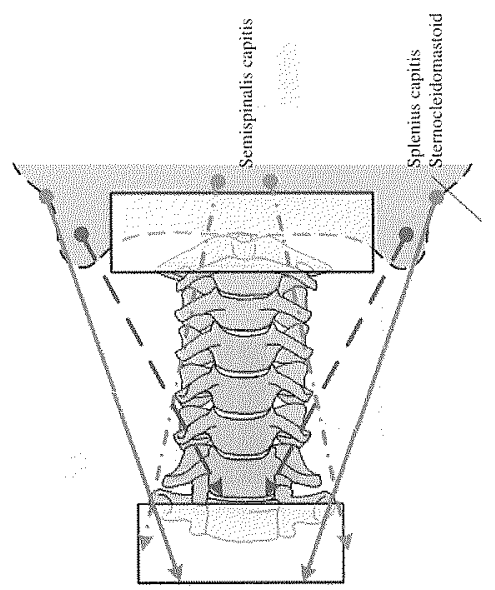

(a)

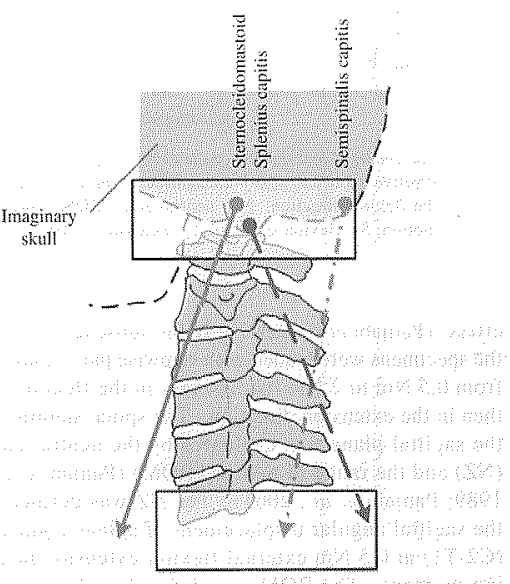

(b)

Fig. 2 Schematic plot for the arrangement of the muscles on the specimen. (a) coronal view; (b) sagital view:

\section{Experimental Procedure and Measurement}

The experiment included the following five muscle recruitment conditions: 1) no muscle recruitment; 2) normal muscle recruitment; 3) right side SCM dysfunction without compensation; 4) right side SCM dysfunction with minimal muscle force compensation strategy; and 5) right side SCM dysfunction with minimal axial force compensation strategy. The muscle forces in normal muscle recruitment lest were calculated by the following conditions: 1) the net moments of three axes were zero; 2) the resultant shear force in lateral direction was zero; 3 ) the resultant axial force was $85 \mathrm{~N}$ (Snijders ef al., 1991); and 4) the summation of square muscle forces was minimum. The muscle force of impaired SCM was set to be $4 \mathrm{~N}$, about $1 / 4$ of that in normal muscle recruitment test. Then the other muscle forces in right side SCM dysfunction with minimal muscle force compensation test were derived from the following conditions: 1) the net moments of three axes were zero; 2 ) the resultant shear force in anteroposterior direction was the same as that in nomal musclere. cruitment test; and 3 ) the summation of square muscle forces was minimuth The other muscle forces in right side SCM dysfunction with minimal axial force compensation test were derived from the samefirst two conditions as those in SCM dysfunction with minimal muscle force compensation test, and the cost function was changed to be: the summation of square axial forces. The first wo conditions for the two compensation strategies were to minimize the changes of initial position in compensation tests from that in nomal muscle recruitment test, and the cost functions were to minimize energy expenditure and com pressive stress respectively. The summaty of the muscle forces is shown in Table 1.

In the beginning of each test, the intial positions in three planes and the resultant axial force at C7-T1 disc $\left(F_{z}\right)$ of the specimens were recorded. The specimens were preconditioned by loading and moloading at $2 \mathrm{Nm}$ for three cycles to eliminate the viscoelastic 


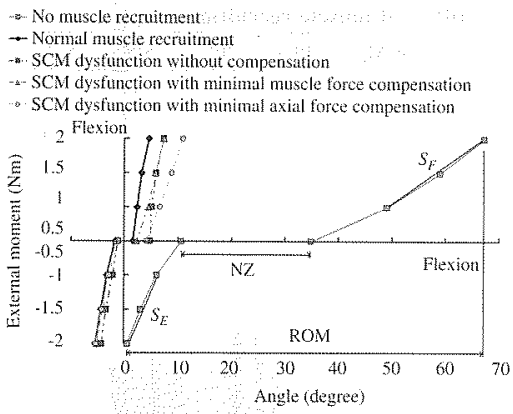

Fig. 3 The averaged load-displacement curve of spinat specimen. Positive angle and positive magnitude of monent indicate the flexion direction. NZ; neutral zone; ROM; range of motion; $S_{F}$ : flexion stifnes; $S_{f}$ extension stiffness

effects (Panjabi etal, 2001). In the subsequent cycle, the specimens were loaded with stepwise pure moments from $0.5 \mathrm{Nm}$ to $2 \mathrm{Nm}$ increasingly in the flexion and then in the extension direction. The spinal stability in the sagittal plane was evaluated by the neutral zone (NZ) and the range of motion (ROM) (Panjabiet al., 1989; Panjabi et al., 2001)." The NZ was defined as the sagittal angular displacement of spinal segments (C2-T1) at $0.5 \mathrm{Nm}$ external flexion-extension bending moment. The ROM was defined as the sagittal angular displacement of spinal segments at $2 \mathrm{Nm}$ external hlexion-extension bending moment. The stiffness of the specimens during flexion and extension motion $\left(S_{F}\right.$ and $\left.S_{E}, N m /{ }^{\circ}\right)$ were defined as the slope of load-displacement curve between $1 \mathrm{Nm}$ and $2 \mathrm{Nm}$ external moments. The initial position of the normal muscle recruitment test was assumed to be the neutral position. The $\theta_{x}, \theta_{y}, \theta_{z}$ were defined as the differences of initial positions between normal muscle recruitment test and other tests in sagittal, coronal, and axial planes respectively. Positive angles of $\theta_{x}, \theta_{y}, \theta_{z}$ mean the shifted positions from the neutral toward flexion, right lateral bending, and right axial rotation directions. The measurements of current study included the NZ, ROM, $S_{F}, S_{E}, \theta_{x}, \theta_{y}, \theta_{z}$, and $F_{z}$. Analysis of variance (ANOVA) was used to examine the effect of different muscle conditions on these measurements. Multiple comparisons anong the five test groups were also conducted. The significance level was set at 0.05 .

\section{RESULTS}

The averaged load-displacement curve showed that the initial position of specimens without muscle recruitment was in flexion direction $\left(14.8^{\circ}\right)$ compared

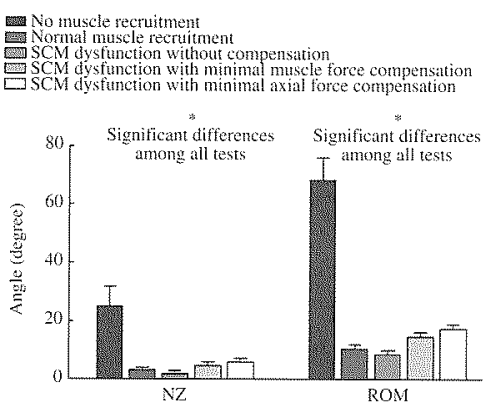

(a)

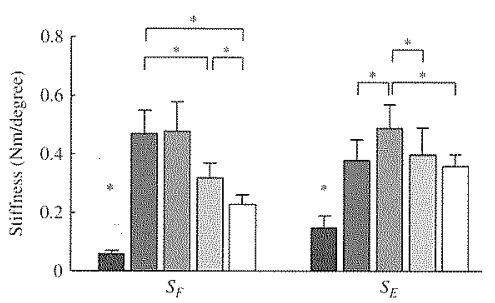

(b)

Fig. 4 The mean and standard devation of: (a) the neutral zone (NZ) and range of motion (ROM), and (b) the flexion and extension stifness $\left(S_{F}, S_{E}\right)$ in diflerent musele conditions. $\therefore: P<0,05$

to the one with normal muscle recruitment. The flexion angle at $2 \mathrm{Nm}$ external moments of no muscle recruitment specimen was up to $68^{\circ}$ and the extension angle was close to $0^{\circ}$ (Fig. 3). The NZ and ROM of no muscle recruitment specimen were $25.1^{\circ} \pm 6.8^{\circ}$ and $68.5^{\circ} \pm 7.7^{\circ}$, respectively. The rotational stiffness of no muscle recruitment specimen of extension $\left(S_{E}\right.$ : $0.15 \pm 0.04 \mathrm{Nm} /{ }^{9}$ ) was higher than the one of flexion $\left(S_{F}: 0.06 \pm 0.0 \mathrm{I} \mathrm{Nm}^{\circ}{ }^{\circ}\right.$. Compared to the no muscle recruitment test, the muscle recruitment tests showed significantly decreased $\mathrm{NZ}\left(1.8^{\circ} \sim 5.9^{\circ}\right)$ and $\mathrm{ROM}$ $\left(8.4^{\circ} \sim 17,4^{\circ}\right)$, and increased flexion and extension stiffiness (up to $0.49 \mathrm{Nm} /{ }^{\circ}$ ) of the specimens (all $P<$ 0.001, Fig. 4 and Table 2).

The NZ and ROM were $3.2^{\circ} \pm 0.8^{\circ}$ and $10.5^{\circ}$ $\pm 1.3^{\circ}$ in the normal muscle recruitment test. Considering the NZ and ROM of normal muscle recruitment as a base for comparison, the SCM dysfunction without compensation strategy decreased NZ and ROM to $1.8^{\circ} \pm 1.1^{\circ}$ and $8.4^{\circ} \pm 1.6^{\circ}(P=0.012)$. However, the $\mathrm{NZ}$ and ROM of the two compensation tests were 
Table 2 Mean \pm standard deviation of all measurements in five muscle recruitment tests

\begin{tabular}{|c|c|c|c|c|c|}
\hline & $\begin{array}{l}\text { No muscle } \\
\text { recruitment }\end{array}$ & $\begin{array}{c}\text { Normal } \\
\text { muscle } \\
\text { recruitment }\end{array}$ & $\begin{array}{c}\text { SCM } \\
\text { dysfunction } \\
\text { without } \\
\text { compensation }\end{array}$ & $\begin{array}{c}\text { SCM } \\
\text { dysfunction } \\
\text { with minimal } \\
\text { compensele force } \\
\text { compation }\end{array}$ & $\begin{array}{l}\text { SCM } \\
\text { dysfunction } \\
\text { with minimal } \\
\text { axial force } \\
\text { compensation }\end{array}$ \\
\hline NZ $\left(^{\circ}\right)$ & $25.1 \pm 6.8$ & $3.2 \pm 0.8$ & $1.8 \pm 1.1$ & $4.7 \pm 1.1$ & $5.9 \pm 1.1$ \\
\hline ROM $\left(^{\circ}\right)$ & $68.5+7.7$ & $10.5 \pm 1.3$ & $8.4 \pm 1.6$ & $14.6 \pm 1.7$ & $\therefore \quad 17.4 \pm 1.4$ \\
\hline$S_{F}\left(\mathrm{Nm} /{ }^{\circ}\right)$ & $0.06 \pm 0.01$ & $0.47 \pm 0.08$ & $0.48 \pm 0.10$ & $0.32 \pm 0.05$ & $0.23 \pm 0.03$ \\
\hline$S_{E}\left(\mathrm{Nm} /{ }^{\circ}\right)$ & $0.15 \pm 0.04$ & $0.38 \pm 0.07$ & $0.49 \div 0.08$ & $0.40 \pm 0.09$ & $0.36 \pm 0.04:$ \\
\hline$\left.\theta_{x}{ }^{\circ}\right)$ & $14.8 \pm 0.8$ & - & $4.1 \pm 1.2$ & $-0.1 \pm 0.7$ & $-0.5 \pm 1.0 \ldots$ \\
\hline$\hat{\theta_{y}}\left({ }^{\circ}\right)$ & $0.6 \pm 1.6$ & - & $-7.2 \pm 1.6$ & $-0.6 \pm 1.4$ & $31 \pm 1.5$ \\
\hline$\theta_{i}\left({ }^{\circ}\right)$ & $0.6 \pm 1.5$ & - & $3.5 \pm 0.7$ & $0.1 \pm 0.7$ & $0.7 \pm 1.0$ \\
\hline$F_{z}(\mathrm{~N})$ & - & $78.0 \pm 0.8$ & $67.8 \pm 0.9$ & $43.0 \div 0.7$ & $42.0 \pm 0.6$ \\
\hline
\end{tabular}

NZ: neutral zone; ROM: range of motion; $S_{F}$ : flexion siffnes; $S_{\vec{E}}$ : extension stifness; $\theta_{y}, \theta_{y}, \theta_{t}$ : the differences of initial positions from those in normal muscle recruitment test in sagital, coronat, and axial planes respectively, $F_{z}$, resultant axial force.

both significantly Jarger than the ones of normal muscle recruitment test (all $P<0.01$ ). The NZ and ROM of SCM dysfunction with minimal axial force compensation test $\left(5.9^{\circ} \pm 1.1^{\circ}\right.$ and $\left.17.4^{\circ} \pm 1.4^{\circ}\right)$ were larger than those with minimal muscle force compensation test $\left(4.7^{\circ} \pm 1.1^{\circ}\right.$ and $\left.14.6^{\circ} \pm 1.7^{\circ}\right)($ all $P<0.05$, Fig. $4(\mathrm{a}))$.

The stiffness in SCM dysfunction without compensation test $\left(S_{F}\right.$ and $S_{E}$ were $0.48 \pm 0.10 \mathrm{Nm} /$ and $0.49 \pm 0.08 \mathrm{Nn} /{ }^{\circ}$ respectively) were significantly higher than the ones in other recruitment tests (all $P$ $<0.01)$. The $S_{F}$ of normal muscle recruitment test $\left(0.47 \pm 0.08 \mathrm{Nm}^{\circ}\right)$ was larger than the one of SCM dysfunction with ninimal muscle force compensation lest $\left(0.32 \pm 0.05 \mathrm{Nm} /{ }^{\circ}, P<0.001\right)$ and with minimal axial force compensation test $\left(0.23 \pm 0.03 \mathrm{Nm} /{ }^{\circ}, P<\right.$ $0,001)$. The $S_{F}$ of SCM dysfunction with minimal muscle force compensation test was also significantly largen than the one with minimal axial force compensation test $(P=0.019)$. There were no significant differences of $S_{E}$ anong the nomal muscle recrutment test and the two compensation tests $(0.36 \sim 0.40$ Nm/ $/^{\circ}$ ) (Fig. $\left.4(\mathrm{~b})\right)$.

Considering the initial position of normal muscle recruitment test as the neutral position, the initial position of no muscle recruitment showed large diversion toward flexion direction $\left(\theta_{x}: 14.8^{\circ} \pm 0.8^{\circ}\right)$ while the diversion in coronal and axial plane were very small (around $0.6^{\circ} \pm 1.6^{\circ}$ ). In SCM dysfunction without compensation test, the initial position of specimen twisted toward extension $\left(\theta_{x}:-4.1^{\circ} \pm 1.2^{\circ}\right)$, left lateral bending $\left(\theta_{y}:-7.2^{\circ} \pm 1.6^{\circ}\right)$, and right axial rotation $\left(\theta_{z}: 3.5^{\circ} \pm 0.7^{\circ}\right)$ directions. The differences of initial position in three planes $\left(\theta_{x}, \theta_{y}\right.$, and $\left.\theta_{z}\right)$ in SCM dysfunction without compensation test were all significantly targer than those in both the compensation tests (all $P<0.001$ ). The differences of initial

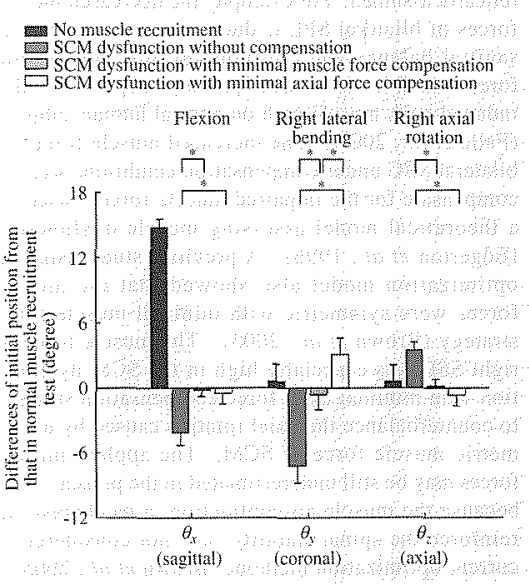

Fig. 5 The differences of the nitial position from that in normal muscle recruitment test in sagital, coronal, andaxial planes $\left(\theta_{x}, \theta_{y}, \theta_{3}\right)$. Positive angles mean the flexion, right lateral bending, and right axial rotation directions, $x<$ 0.05

position $\left(\theta_{x}, \theta_{y}\right.$, and $\left.\theta_{i}\right)$ were mostly smaller than $1 \%$ whth muscle compensation strategies. There were no significant differences of initial positions between the two compensation tests except in coronal plane, ie: $\theta_{y}$ was $-0.6^{\circ} \pm 1.4^{\circ}$ in $\mathrm{SCM}$ dysfunction with mintmal muscle force compensation test and $3,19+1,5$ in SCM dysfunction with minimal axial force compensation test $(P=0.001$, Fig. 5$)$.

The nomal muscle recribtment resulted in largest axial force $(78.0 \pm 0.8 \mathrm{~N}, P<0.001)$. The axial force in SCM dysiunction without compensation test 
$(67.8 \pm 0.9 \mathrm{~N})$ was also larger than the axial force of the two compensation tests $(P<0.001)$. The axial Corce of SCM dysfunction test with minimal axial force compensation $(42.0+0.6 \mathrm{~N})$ was smaller than the one with minimal muscle force compensation test $(43.0 \pm 0.7 \mathrm{~N})(P=0.015$, Table 2$)$.

\section{DISCUSSION}

This study: investigated the relationship between the stability of cervical spine and unilateral SCM dystunction with different compensation strategles. Muscle strength decreases because of injury, fatigue, aging, and degeneration, but it does not reach zero (Mayer et al, 1985), Thus the impared SCM muscle force in this study was set to be about $1 / 4$ of normal muscle force. The compensatory muscle forces illustrated in Table I were clinically observed or theoretically assumed. For example, the decreased muscle forces of bilateral SPL is due to the maintenance of sagitcal balance and constant cervical contraction force, which is the result of previous experimentallyinduced neek muscle pain on normal human subjects (Falla et al., 2007). The increased muscle forces of bilateral SSC under compensation conditions were to compensate for the impared muscle forces based on a theoretical model assessing muscle dysfunction (Edgerton et al., 1996). A previous study using an optimization model also showed that the muscle forces were symmetric with minimal muscle force strategy (Brown el al., 2005). The muscle force of right $\$$ SC was especially high in the SCM dysfunction with minimal axial force compensation strategy to counterbalance the axial rotation caused by asymmetric muscle force of SCM. The applied muscle forces may be still underestimated in the present study because the muscle comcontraction, a mechanism to reinforce the spinal stability, was not considered in current optimization methods (Brown et al., 2005).

The stiffness, ROM, and NZ of the specimen were generally used to quantify the intervertebral stability. The three parameters represented the rate, maximal, and minimal intemal resistance opposed to the external load respectively. Segmental instability can be indexed by reduced stiffness or incrensed ROM and NZ. The bending stiffness was defined as the slope of the load-displacement curve (Wilke et al., 1994). The ROM of the multi-segmental cervical spine was measured by given assumed maximal external pure moment from $1 \mathrm{Nm}$ to $2: 5 \mathrm{Nm}$ (Panjabi et al., 2001; Pizen et al, 2007; Wilke et al., 1997). The NZ is commonly used to measure the displacement at which the resistance of movement is detected. Panjabi et at. (2001) defined the NZ as the angular rotation withouf external load to highlight the viscoelastic behavior. The definition of $\mathrm{NZ}$ in the current study was the angular rotation under fixed external load (i.e. $0.5 \mathrm{Nm}$ ) which provided larger but stable measurement (Zhao et al., 2005).

Cautions should be used when interpreting the results. To simplify the study design, fixed sets of parameters, such as the muscle orientation, disc load, and muscle forces, were used without dealing with the geometric differences of specimens. Besides, those parameters were from the normal human model and were applied to all porcine specimens. This study was to determine the mechanism of how the muscle dysfunctions and compensations affect the cervical spine stability. Human cadaveric specimens were not used due to poor accessibility, uncontrolled bone quality due to age, and cost. This study showed that the length of the porcine cervical spines (C2- TI, $14.9 \mathrm{~cm}$ ) was longer than the reported length of human cervical spine (C3-T1, $9.5 \mathrm{~cm}$ ) (Kandziora et al., 2001; Tan et al, 2004). The average stiffness under flexion/extension external moments in this study was $0.11 \pm 0.06 \mathrm{Nm} /$ degree, and was $0.07 \pm 0.02 \mathrm{Nm} / \mathrm{de}-$ gree in human specimens (C2-T2) (Ouyang et al., 2005). The ROM of $2.0 \mathrm{Nm}$ external load in this study was $68.5^{\circ}$ and was close to the ROM of a human specimen $\left(73.0^{\circ}, \mathrm{C} 2-\mathrm{T}\right.$ ) ) (Wheeldon et al., 2006). The NZ of the porcine cervical spine $\left(25.1^{\circ}\right)$ was, however, larget than the $\mathrm{NZ}$ of a human spine $\left(14.0^{\circ}, \mathrm{C} 2-\mathrm{C} 7\right)$ (Panjabi et al., 2001). The specimen length and the shape of the facet joint between the porcine spine and human spine (Wang et al, 2004; Yingling ef al., 1999) may be different. Nevertheless, the kinematic behaviors between human and porcine models without muscle recruitment may be considered comparable.

The SCM dysfunction without compensation test showed the smallest NZ and ROM. It should be noted that this test also showed large twisted initial positions in three planes $\left(\theta_{x}, \theta_{y}\right.$, and $\left.\theta_{z}\right)$. The bias position may constrain the spinal movement and show "locking" phenomena violating the clinical manifestations. This study suggested that the compensation strategy should be considered in the in vitro study when investigating unilateral muscle dysfunction.

There were significant increases of $\mathrm{NZ}$ and ROM in the two compensation tests compared to the ones in the normal muscle recrutment test. Thus the muscle dysfunction with compensation strategies wolld not provide efficient spinal stability as the normat muscle did. The NZ and ROM in SCM dysfunction with minimal muscle force compensation test were smaller, but the flexion stifness $\left(S_{F}\right)$ and axial force $\left(F_{z}\right)$ were larger than the ones in SCM dysfunction with minimal axial lorce compensation test. The minimal muscle force compensation strategy was presumed to minimize the energy expenditure, while the minimal axial force compensation strategy was to minimize the compressive stress on the intervertebral 
disc (Brown et al, 2005). The minimization of muscle force was therefore suggested to be a more desirable compensation strategy over the minimization of axial force since it decreases the consumed energy, maintains better spinal stability, and only increases intradiscal load $\left(F_{*}\right)$ a small amotnt.

A previous study demonstrated that the NZ, ROM, and bending stiffness are complementary expressions of stability, and are highly correlated with each other (Zhao ef al., 2005), In other words, the spinal stabil. ity in terms of stiffness corresponds to the observation from the NZ and ROM. However, the $S_{F}$ in the current study was significantly different among the normal muscle recruitment test and the two compensation tests, but the $S_{E}$ was not. This may be due to the extension stifness which was constrained by strong neck flexors failing to reflect the subtle differences among different muscle recruitments. Thus the $S_{F}$ could be a more sensitive index for examination of the stiffness of specimen with muscle recruitments.

The results of the present experiment indicated that muscle dysfunction affects the spinal stability. The study design focused on sub-acute muscle injury stage (i.e., the muscle spasm response subsides). with nomal CNS control (capable of generating the "optimal" strategy). This study revealed an important clinical implication, that the cervical spine stability may not be sufficiently maintained in patients suffering cervical muscle dysfunction. If the impaired muscles are not treated properly (e.g. muscle re*edu* cation or strengthening exercises), the prolonged muscle dysfunction may induce permanent modification of CNS control pattern from altered neural input and changed muscle properties (Falla et al., 2008). The abnormal control pattern would shift loads to the intervertebral discs and ligaments, decrease the role of the facet joint in transmitting load and stabilizing the spine (Goel et al., 1993; Kong et al., 1996), and then cause chronic pain eventually (Panjabi, 1992). Further study can include the pain-adaptation model in the chronic stage of muscle dysfunction (Lund et al., 1991) to conplement the understanding between the muscle dysfunction and the spinal stability.

\section{CONCLUSIONS}

This in vitro study showed that the simulation of muscle dysfunction without proper compensation strategy would result in twisted posture of the specimen and restricted spinal motion. Thus the investigation of the unilateral muscle dysfunction in the in vitro study should incorporate compensation strategies. The impaired muscle with surounding muscle compensations cottd not efficiently stabilize the cervical spine as the nomal muscles did. The optimal condition with minimal muscle forces was suggested to provide better spinal stability than that with minimal axial forces. The current study demonstrated the potential to incorporate the presumed CNS control strategies into the in vitro study. More complex muscle interactions and their effects on the different kinds of spinal injury can be studied in the future.

\section{ACKNOWLEDGEMENT}

National Health Research Institute, Taiwan (NHRI-EX96-9425EI),

\section{REFERENCE}

Andersen, J.H.; Haahr, J. P., and Frost, P., 2007, "Risk Factors for More Severe Regional Musculoskeletal Symptoms: A Two Year Prospective Study of a General Working Population, Arthritis and Rheumatism, Vol, 56, No, 4, pp. 13551364.

Arjmand, N., and Shirazi-Adl, A, 2006, Sensitivity of Kinematics-Based Model Predictions to Optimization Criteria:in Static Lifting Tasks, Medical Engineering and Physics, $\mathrm{Vol}, 28, \mathrm{No} 6, \mathrm{pp}$ 504-514.

Brown, S. H., and Potvin, J, R, 2005, Constraining Spine Stability Levels in an Optimization Model Leads to the Prediction of Trunk Muscle Cocontraction and Improved Spine Compression Force Estimates, Joimal of Biomechanics, Vol. 38, No. 4, pp. 745-754.

Buchanan, T.S., and Shreeve, D. A, 1996, AAn Evaluation of Optimization Techniques for the Prediction of Muscle Activation Patterns During Isometric Tasks," Joumal of Bionechanical Engineering, Vol 118, No 4, pp 565574 .

Choi, H., and Vanderby, R.J. 1999, "Comparison of Biomechanical Human Neck Models: Muscle Forces and Spinal Loads at C4/5 Level, Joumal of Applied Biomechanics, Voll 15, No 2, pp.120138.

Crisco, J.J., 3rd, and Panjabi, M. M., 1991, The Intersegmental and Multisegmental Muscles of the Lumbar Spine A Biomechanical Model Compar. ing Lateral Stabilizing Potential, Spine, Vol.16, No. 7, pp. 793-799.

Edgerton, V. R., Wolf, S. L., Levendowski, D. J, and Roy, R. R., 1996, "Theoretical Basis for Patterning EMG Amplitudes to Assess Muscle Dysfunction," Medicine and Science in sports and Exercise, Vol. 28, No. 6, pp 744751

Essendrop, M., Andersen, T. B, and Schibye, B. 2002, "Increase in Spinal Stability Obtained at Levels of Intra-Abdominal Pressure and Back Muscle Activity Realistic to Work Situations," 
AppliedErgonomics, Vol. 33, No. 5, pp. 471-476 Falla, D., Fanina, D., Dahl, M. K., and Graven-Nielsen, T., 2007. "Muscle Pain Induces Task-Dependent Changes in Cervical Agonist/Antagonist Activity," Journal of Applied Physiology, Vol. 102, No. 2, pp. $601-609$

Falla, D., and Farina, D., 2008, "Neuromuscular Adaptation in Experimental and Clinical Neck Pain," Jounal of Electromyography and Kinesiology, Vol. 18, No. 2, pp. 255.26I.

Goel, V, K, Kong, W., Han, J: S., Weinstein, J. N., and Gilbersson, L. G., 1993, "A Combined Finite Element and Optimization Investigation of Lumbar Spine Mechanics with and withont Muscles," Spine, Vol. 18, No. 11, pp. 1531-1541

Hughes, R. E., Chaffin, D, B., Lavender, S. A., and Andersson, $G \cdot B, \cdot 1994$; "Evaluation of Muscle Force Prediction Models of the Lumbar Trunk Using Surface Electromyography." Journal of Orthopaedic Research, Vol. 12, No. 5, pp. 689. 698.

Kandziona, F., Pflugmacher, R., Seholz, M., Schnake, K., Lucke, M, Schroder, R., and Mittmeier, T., 2001,"Comparison between Sheep and Human Cervical Spines: An Anatomic, Radiographic, Bone Mineral Density, and Bionechanical Study," Spine, Vol. 26, No. 9; pp. 1028-1037.

Kettler, A., Hantwig, E., Schultheiss, M., Claes, L., and Wilke, H. J., 2002, "Mechanically Simulated Muscle Forces Strongly Stabilize Intact and Injured Upper Cervical Spine Specimens," Joumal of Biomechanics, Vol. 35. No. 3, pp. 339-346.

Kong, W. Z., Goel, V. K, Gilbertson, L. G., and Weinstein, J. N., 1996, "Effects of Muscle Dysfunction on Lumbar Spine Mechanics. A Finite Element Study Based on a Two Motion Segnents Model,"Spine, Vol. 21, No. 19, pp. 2197-2206; discussion 2206-2197

Langenderfer, J., LaScalza; S., Mell, A., Carpenter, J. E, Kuhn, J. E., and Hughes, R. E., 2005, "An EMG-Driven Model of the Upper Extremity and Estimation of Long Head Biceps Force," Computers in Biology and Medicine, Vol. 35, No. 1, pp. 25-39.

Lee, P. J., Rogers, E. L., and Granata, K. P., 2006 , "Active Trunk Stiffness Increases with Cocontraction," Journal of Electromyography and Kinesiology, Vol. 16, No. 1, pp. 51-57.

Lund, J. P., Donga, R., Widmer, C. G., and Stohler, C. S., 1991, "The Pain Adaptation Model: A Dis" cussion of the Retationship between Chronic Musculoskeletal Pain and Motor Activity," Canadian Joumal of Physiology and Pharmacology. Vol. 69 ; No. 5 , pp. 683-694.

Mayer, T. G., Smith, S. S., Keeley, J, and Mooney, V., 1985, "Quantification of Lumbar Function.
Part 2: Sagital Plane Trunk Strength in Chronic Low-Back Pain Palients," Spine, Vol. 10, No. 8 . pp. $765-772$.

Moroney, S. P., Schuliz, A. B, and Miller, J. A., 1988 , "Analysis and Measurement of Neck Loads," Joumal of Orthopaedic Research, Vol, 6, No. 5 , pp. $713-720$.

Nachemson, A., 1985, "Lumbar Spine Instability. A Critical Update and Symposian Summary," Spine, Vol. 10, No. 3, pp. 290-291.

Ouyang, J., Zhu, Q., Zhao, W., Xu, Y., Chen, W., and Zhong, S., 2005, "Biomechanical Assessment of the Pedianric Cervical Spine under Bending and Tensile Loading," Spine, Vol. 30, No. 24, pp. E7 16-723.

Panjabi, M. M., Abuni, K., Duranceau, J, and Oxland, T., 1989, "Spinal Stability and Intersegmental Muscle Forces. A Biomechanical Model," Spine, Vol. 14, No. 2, pp. 194-200.

Panjabi, M. M., 1992," The Stabilizing System of the Spine. Pan 1. Function, Dysfunction, Adaptation, and Enhancement," Journal of Spinal Disorders, Vol. 5, No. 4, pp. 383-389; discussion 397.

Panjabi, M. M., Crisco, J. J., Vasavada, A., Oda, T., Cholewicki, J., Nibu, K, and Shin, E., 2001, "Mechanical Properties of the Human Cervical Spine as Shown by Three-Dimensional Load-Displacement Curves," Spine, Vol. 26, No.24, pp. 2692-2700.

Panjabi, M. M., 2007, "Hybrid Multidirectional Test Method to Evaluate Spinal Adjacent-Level Effects," Clinical Biomechanics, Vol. 22, No. 3 , pp. 257-265.

Pitzen, T., Kettler, A., Drumm, J., Nabhan, A., Steudel, W. I., Claes, L., and Wilke, H. J., 2007. "Cervical Spine Disc Prosthesis: Radiographic, Biomechanical and Morphological Post Mortal Findings 12 Weeks after Implantation. A Retrieval Example," European Spine Joumal, Vol. 16, No. 7, pp. 1015-1020.

Snijders, C. J., Hoek van Dijke, G. A., and Roosch, E. R., 1991, "A Biomechanical Model for the Analysis of the Cervical Spine in Static Postures,"Joumal of Biomechanics, Vol. 24. No. 9, pp. 783-792.

Tan, S. H., Teo, E. C., and Chua, H. C., 2004, "Quantitative Three-Dimensional Anatomy of Cervical, Thoracic and Lumbar Ventebrae of Chinese Singaporeans," European Spine Joumal, Vol. 13 , No. 2, pp. $137-146$.

Vasavada, A. N., Li, S., and Delp. S. L., 1998, "Intuence of Muscle Morphometry and Moment Arms on the Moment-Generating Capacity of Human Neck Muscles." Spine, Vol. 23, No. 4, pp. 412-422.

Wang, J. L., Tsai, Y. C., and Yang, B. D., 2004. "Strain Energy Density Distribution of Vertebral 
Body of Two Motion Segment Model under Combined Compression and Sagiral Bending Momentan in Vitro Porcine Spine Biomechanical Study," Joumal of the Chinese Institute of Engineers, Vol. 27. No. 6, pp. 927-934.

Wheeldon, J. A., Pintar, F. A., Knowles, S., and Yoganandan, N., 2006, "Experimental Flexion/ Extension Data Corridors for Validation of Finite Element Models of the Young, Normal Cervical Spine," Journal of Biomechanics, Vol. 39 , No. 2 , pp. $375-380$.

Wilke, H. I., Claes, L., Schmitt, H., and Wolf, S., 1994, "A Universal Spine Tester for in Vitro Experiments with Muscle Force Simulation," European Spine Joumal, Vol. 3, No. 2, pp. 91-97.

Wilke, H. J., Wolf, S., Claes, L. E., Arand, M., and Wiesend, A., 1995, "Stability Increase of the Lumbar Spine with Different Muscle Groups. A Biomechanical in Vitro Study," Spine, Vol. 20,
No. 2, pp. 192-198.

Wilke, H. J., Kettler, A., and Claes, L. E., 1997, "Are Sheep Spines a Valid Biomechanical Model for Human Spines?," Spine, Vol. 22, No. 20, pp. 2365-2374.

Yingling, V. R., Callaghan, J. P., and McGill, S. M., 1999, "The Porcine Cervical Spine as a Model of the Human Lumbar Spine: An Anatomical, Geometric, and Functional Comparison," Joumal of Spinal Disorders, Vol. 12, No. 5, pp. 415-423.

Zhao, F., Pollintine, P., Hole, B. D., Dolan, P., and Adams, M. A., 2005, "Discogenic Origins of Spinal Instability," Spine, Vol. 30, No. 23, pp. 2621 2630 .

Manuscript Received: Oct. 04, 2007 Revision Received: Feb. 19, 2008 and Accepted: Mar, 19, 2008

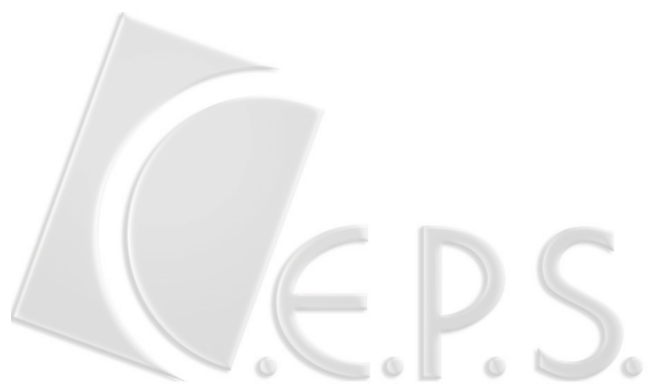

